\title{
Suitability of various prey types for the development of Propylea japonica (Coleoptera: Coccinellidae)
}

\author{
SHI-Ze ZHANG ${ }^{1}$, FAN ZHANG ${ }^{2 *}$ and BAO-ZHEN HUA ${ }^{1}$ \\ ${ }^{1}$ College of Plant Protection, Northwest Sci-Tech University of Agriculture and Forestry, Yangling, Shaanxi 712100, China; \\ e-mails: shzzhang@nwsuaf.edu.cn; huabzh@nwsuaf.edu.cn \\ ${ }^{2}$ Institute of Plant and Environmental Protection, Beijing Academy of Agricultural and Forestry Sciences, Banjingcun, Haidian, \\ Beijing 100089, China; e-mail: zf6131@263.net
}

Key words. Coccinellidae, Propylea japonica, prey suitability, Bemisia tabaci eggs, B. tabaci nymphs, Myzus persicae, biological control

\begin{abstract}
The relative suitability of three prey organisms, Bemisia tabaci (Gennadius) eggs, B. tabaci nymphs, and Myzus persicae (Sulzer), to the ladybird Propylea japonica (Thunberg) was evaluated under laboratory conditions. The larvae developed fastest when fed M. persicae, and slowest on B. tabaci eggs. When fed M. persicae, all larvae successfully developed into adult with a growth index (i.e., percent pupation/larval period in days) of 13.16 and development rate of 0.096 . The longevity of starving adults was $4.7 \pm 0.2$ days. In contrast, when fed $B$. tabaci eggs, all larvae survived to the second instars, $56.7 \%$ of which survived to the third instars, $13.3 \%$ to the fourth instars; only $6.7 \%$ of larvae survived to the pupal stage and the pupae developed into abnormal adults that died shortly. When fed B. tabaci nymphs, all larvae survived and successfully developed into adults with a growth index of 10.71 and development rate of 0.083 . The adult body mass was greater when larvae fed $M$. persicae, compared to adults eclosing from larvae fed $B$. tabaci nymphs. On the basis of these findings, the order of suitability of three prey organisms for $P$. japonica is M. persicae $>$ B. tabaci nymph $>B$. tabaci egg. This is the first record that $P$. japonica can complete its development when feeding exclusively on whitefly nymphs.
\end{abstract}

\section{INTRODUCTION}

The cotton whitefly Bemisia tabaci (Gennadius), occurring worldwide in tropical and subtropical climates (Jiang et al., 1999; Hilje et al., 2001) as well as in protected agricultural systems in temperate regions (Brown et al., 1995), is a severe pest of numerous field and vegetable crops in many parts of the world (Gerling et al., 2001), attacking more than 600 plant species (Secker et al., 1998). The whitefly causes damage through feeding, honeydew production and resultant sooty mold, and disease transmission (Jones, 2003). Although this pest has been known as a sporadic pest of cotton in China for a long time, its B-biotype has not become an important pest in northern China until 2000 (Wu et al., 2002) and has spread to 19 provinces to date (Ren et al., 2001). Many attempts have been made to control B. tabaci. Because of their high reproductive rate, multiple generations per year (Byrne \& Bellows, 1991; Brown et al., 1995), and ability to rapidly develop resistance to insecticides (Palumbo et al., 2001), the whitefly is very difficult to control through conventional approaches. Thus, biological control becomes the primary method to suppress whitefly populations in agroecosystems.

In developing an effective IPM program to control B. tabaci, it would be advantageous to maximize the effectiveness of several natural enemies. The predaceous coccinellids are important natural enemies of several small phytophagous insects and acarines and are therefore considered as potentially good biocontrol agents (Obrycki \& Kring, 1998). The ladybeetle Propylea japonica (Thunberg) is one of the predominant species of predators in northern China, preferentially preying on young larvae and eggs of many insect pests in the field and greenhouse vegetables. It is considered one of the best biocontrol agents in this arid and semi-arid area (Jing et al., 2002; Zhang et al., 2004). The green peach aphid Myzus persicae (Sulzer), a severe pest on vegetables, stone fruit trees and tobacco throughout the world, causes damage to crops by direct feeding, but also serves as a vector for over 100 plant viruses, is one of the major prey species of $P$. japonica. During our investigation, the ladybird was frequently found in association with not only the green peach aphid but also with whiteflies in vegetable fields in northwestern China. This prompted us to speculate that $P$. japonica could prey on $B$. tabaci.

Measuring the voracity of predators is an important step in assessing the potential of a biological control agent. For generalist predators, however, the simultaneous presence of numerous pest species in the field can invalidate the results obtained in the laboratory with a single species of prey. Studying prey suitability for a predator is one of the important steps to evaluate the potential of the predator being used in biological control programmes for insect pests, which may determine the success or failure of predators in biological control systems (Thompson, 1951). In this study, larval development, survival rate, adult body mass and longevity of $P$. japonica were measured to quantify the suitability of three prey items, $B$. tabaci eggs, $B$. tabaci nymphs and $M$. persicae.

\section{MATERIAL AND METHODS}

$P$. japonica adults and M. persicae, collected from the experimental farm of the Northwest Sci-Tech University of Agriculture and Forestry, were reared in the laboratory. In the experimental farm, the ladybird was frequently found in association with not only the green peach aphid but also with whiteflies. To obtain the desired stage of $P$. japonica, pairs were

\footnotetext{
* Corresponding author.
} 
transferred onto cabbage leaves infested with $M$. persicae in round jars $(8.0 \mathrm{~cm}$ in diameter and $10 \mathrm{~cm}$ in height $)$ and kept at $25 \pm 1{ }^{\circ} \mathrm{C}, 60-70 \% \mathrm{RH}$, and a photoperiod of $16 \mathrm{~L}: 8 \mathrm{D}$. The leaflet was wrapped in an absorbent cotton ball in the jars covered with fine muslin cloths. The jars were checked daily and aphids were supplied each day. Once oviposition began, males were removed so females could oviposit in isolation; the newly deposited eggs were incubated under the same conditions.

$B$. tabaci was collected from a natural infestation on poinsettia and reared on cabbage plants in mesh covered cages $(60 \times 60 \times 60 \mathrm{~cm})$ in climate chambers $\left(20-30^{\circ} \mathrm{C}, 16 \mathrm{~L}: 8 \mathrm{D}\right)$. To acquire the desired stages of $B$. tabaci, cabbage plants were exposed to $B$. tabaci adults in the stock culture cages for $12 \mathrm{~h}$, and then incubated under the same conditions until the required stage for the experiments was reached. The whiteflies were monitored daily with a stereoscopic binocular microscope to determine the desired developmental stages (third-fourth instar nymphs) for our experiments.

The effects of different prey upon the development and immature survival of $P$. japonica were assessed. One hundred $P$. japonica eggs were collected from the laboratory-maintained stock and kept in a Petri dish $(12.0 \mathrm{~cm}$ in diameter and $2.0 \mathrm{~cm}$ in height) until hatching. Moist filter paper was placed at the bottom of the Petri dish to maintain humidity. The duration of the egg stage was recorded and the first instars were transferred to Petri dishes $(9.0 \mathrm{~cm}$ in diameter and $1.5 \mathrm{~cm}$ in height) using a soft camel hairbrush. The newly hatched first instars were individually placed in close vicinity to the prey. A fine muslin cloth, secured with a rubber band, covered the container.

Aphid prey was supplied on host plant leaves during the entire larval period. Aphids were replaced every $6 \mathrm{~h}$ to avoid microbial contamination. To provide whitefly prey, a cabbage leaf disc $(5 \mathrm{~cm}$ in diameter) with only eggs or nymphs of $B$. tabaci was put into a Petri dish $(9.0 \mathrm{~cm}$ in diameter and $1.5 \mathrm{~cm}$ in height). One first instar $P$. japonica was added to the arena. Afterwards, each $P$. japonica larva was transferred daily to a new arena containing fresh prey. To decide the adult hunger tolerances (i.e., how long the adult ladybirds lived without prey after eclosing), newly emerged $P$. japonica adults (max. $12 \mathrm{~h}$ old) were put singly into Petri dishes with moist filter paper without prey. The adults were inspected every day and the numbers of living and dead adults were recorded. All experiments were conducted in a climatic chamber at temperature of $25 \pm$ $1{ }^{\circ} \mathrm{C}$, RH $60-70 \%$, and a photoperiod of $16 \mathrm{~L}: 8 \mathrm{D}$. Thirty newly hatched $P$. japonica larvae $(<12 \mathrm{~h}$ old $)$ were reared on each kind of prey.

$P$. japonica larvae were checked every $6 \mathrm{~h}$ for eclosion or death. The development duration for each immature stage was recorded for each individual and the newly-emerged P. japon- ica were weighed using a micro-balance (accurate to $0.001 \mathrm{~g}$ ) to record their initial body mass.

Immature survival rate, adult emergence and development rate (1/developmental period) were recorded using the following formulae, and growth index followed the formula proposed by Dubey et al. (1981).

Survival rate $(\%)=$ Number of pupae formed $/$ Number of first instars hatched $\times 100$

Adult emergence $(\%)=$ Number of adults emerged $/$ Number of pupae $\times 100$

Growth index $=$ Percent pupation $/$ Larval period

\section{Data analysis}

Developmental duration of immature stages and overall development of $P$. japonica were analyzed by means of one-way analysis of variance (ANOVA); means were separated by LSD at 0.05 level. The experimental data were analyzed using the statistical package software SPSS 10.0 (2000).

\section{RESULTS}

When reared on $B$. tabaci eggs as prey, 4 of the initial 30 larvae reached the fourth stage (mortality of $86.7 \%$ ), 2 reached the pupal stages (mortality of $93.3 \%$ ); the pupae developed into abnormal adults that died shortly. Because of the very high mortality, the durations of fourth larval and pupal stages could not be compared with those of $P$. japonica feeding on the other two prey types. $P$. japonica larvae feeding on different prey varied significantly in their development duration (Table 1). The duration of first instar was the shortest on $M$. persicae, followed by B. tabaci eggs, and B. tabaci nymphs $(\mathrm{F}=125.505 ; \mathrm{df}=2,89 ; \mathrm{P}$ $<0.001)$. The duration of the second instar was similar when larvae consumed $M$. persicae and B. tabaci nymphs, but longer on $B$. tabaci eggs $(\mathrm{F}=10.663 ; \mathrm{df}=2,89 ; \mathrm{P}<0.001)$. Similarly, the third instars took longer time to develop on $B$. tabaci eggs than on $M$. persicae or B. tabaci nymphs $(\mathrm{F}=39.871$; $\mathrm{df}=2$, 89; $\mathrm{P}<0.001)$. However, the fourth instar duration did not vary significantly between feeding on $M$. persicae or on $B$. tabaci nymphs $(\mathrm{F}=3.6013$; $\mathrm{df}=1,59 ; \mathrm{P}=0.0627)$. The pupal durations of $P$. japonica differed significantly between feeding on M. persicae and on $B$. tabaci nymphs $(\mathrm{F}=4.4658 ; \mathrm{df}=1,59 ; \mathrm{P}$ $=0.0389$ ). The complete developmental period was significantly shorter when feeding on $M$. persicae than on $B$. tabaci nymphs $(\mathrm{F}=69.9027 ; \mathrm{df}=1,59 ; \mathrm{P}<0.001)$.

The body mass of newly emerged adults differed significantly after feeding on $M$. persicae and B. tabaci nymphs (Table 1) (F $=69.9027 ; \mathrm{df}=1,59 ; \mathrm{P}<0.001)$. The adults weighed averagely $6.67 \mathrm{mg}$ when emerging from the larvae predating $M$. persicae, while the lightest adults were those from larvae preying on the

TABLE 1. Durations of life stages of $P$. japonica on three prey items (first and second values in brackets show the numbers of individuals at the start of first instar of the ladybird and numbers of surviving individuals at the end of each stage, respectively ).

\begin{tabular}{lccc}
\hline \multirow{2}{*}{ Stage } & \multicolumn{3}{c}{ Duration (Mean \pm S.E. in days) } \\
\cline { 2 - 4 } & B. tabaci eggs & B. tabaci nymphs & M. persicae \\
\hline First instar & $2.65 \pm 0.09 \mathrm{~b}(30 / 30)$ & $3.13 \pm 0.07 \mathrm{a}(30 / 30)$ & $1.64 \pm 0.04 \mathrm{c}(30 / 30)$ \\
Second instar & $2.47 \pm 0.31 \mathrm{a} \mathrm{(30/30)}$ & $1.62 \pm 0.07 \mathrm{~b}(30 / 30)$ & $1.29 \pm 0.07 \mathrm{bc}(30 / 30)$ \\
Third instar & $3.23 \pm 0.33 \mathrm{a} \mathrm{(30/17)}$ & $1.38 \pm 0.06 \mathrm{~b}(30 / 30)$ & $1.67 \pm 0.07 \mathrm{bc}(30 / 30)$ \\
Fourth instar & $8.25 \pm 0.63(30 / 4)$ & $3.21 \pm 0.03 \mathrm{a}(30 / 30)$ & $3.01 \pm 0.10 \mathrm{a}(30 / 30)$ \\
Pupa & $3.88 \pm 0.32(30 / 2)$ & $2.74 \pm 0.02 \mathrm{~b}(30 / 30)$ & $2.86 \pm 0.05 \mathrm{a}(30 / 30)$ \\
Total immature & $19.11 \pm 1.05$ & $12.08 \pm 0.08 \mathrm{a}$ & $10.46 \pm 0.17 \mathrm{~b}$ \\
Adult body mass $(\mathrm{mg})$ & & $3.40 \pm 0.12 \mathrm{~b}$ & $6.67 \pm 0.18 \mathrm{a}$
\end{tabular}

Means followed by the same letters in the same row are not significantly different at 0.05 level. 
TABLE 2. Growth of P. japonica on three prey items.

\begin{tabular}{lccc}
\hline & B. tabaci eggs & B. tabaci nymphs & M. persicae \\
\hline Immature survival rate (\%) & 6.7 & 100 & 100 \\
Growth index & 0.86 & 10.71 & 13.16 \\
Adult emergence (\%) & 0 & 100 & 100 \\
Development rate (day ${ }^{-1}$ ) & 0.052 & 0.083 & 0.096 \\
Adult longevity with no food (days) & & $3.90 \pm 0.21$ & $4.68 \pm 0.22$ \\
\hline
\end{tabular}

nymphs of B. tabaci (mean $3.40 \mathrm{mg}$, min $1.73 \mathrm{mg}$, max 4.85 $\mathrm{mg})$.

The immature survival rates from the first instar to adult stage differed markedly among larvae feeding on the three prey items (Table 2). When larvae were fed $B$. tabaci eggs, all first instars molted to the second instar, $56.7 \%$ of which molted into third instar, $13.3 \%$ into fourth instar, and $6.7 \%$ successfully pupated None of these pupae completely emerged. However, $100 \%$ of $P$. japonica larvae feeding on either $B$. tabaci nymphs or $M$. persicae survived to adulthood $\left(\chi^{2}=52.500 ; \mathrm{df}=1 ; \mathrm{P}<0.001\right)$.

The developmental rate for $P$. japonica varied from 0.052 to 0.096 on three types of prey (Table 2). The growth index of $P$. japonica was the highest when feeding on $M$. persicae, followed by the group fed nymphs of $B$. tabaci and was lowest on $B$. tabaci eggs as prey. When larvae preyed either on $B$. tabaci nymphs or $M$. persicae, adult longevity under starvation was significantly different $(\mathrm{F}=6.3771 ; \mathrm{df}=1,59 ; \mathrm{P}=0.0143)$.

\section{CONCLUSIONS AND DISCUSSION}

Larval survival rate and growth and adult reproduction rate of coccinellids are closely associated with the quality of prey. Prey quality influences the development, survival and reproduction of coccinellids. Hodek (1996) made a distinction between essential prey and alternative prey for coccinellid predators. Consumption of essential prey provides for growth and development of larvae and reproduction by adults. Alternative prey provides energy and nutrients but does not enable development and reproduction of the coccinellid. The enhanced performance of coccinellid larvae on suitable prey may be due to higher protein levels or increased consumption (Omkar \& Srivastava, 2003). Our study showed that prey species had a substantial effect on the life history of $P$. japonica. $M$. persicae and nymphs of $B$. tabaci were suitable for development of $P$. japonica, satisfying the requirements as an essential prey. $M$. persicae appeared to be a more suitable prey for $P$. japonica than the nymphs of $B$. tabaci by allowing higher larval developmental rates. If $P$. japonica fed only on $B$. tabaci eggs in larval stage, they failed to survive to adult stage, suggesting that $B$. tabaci eggs were not a suitable prey for $P$. japonica larvae. The younger larvae of $P$. japonica may not have very strict nutritional requirements, or they could survive on this prey of poor nutritional value. The older larvae were either very strict for their nutritional requirements, or the poor nutrition in early development created a "nutritional deficit" that must be compensated for successful development. In insects, suppression of growth and developmental rate during the larval stage is likely to affect the size and maturation of adults, which in turn may lead to reduced reproductive success or survivorship.

Several species of Coccinellidae are considered important natural enemies of whiteflies (Obrycki \& Kring, 1998). These include Serangium parcesetosum that feeds on eggs and nymphs of B. tabaci (Legaspi et al., 1996). B. tabaci pupae were more suitable prey for the development of $S$. parcesetosum larvae than nymphs and eggs, while pupae and nymphs were more suitable for the coccinellid females (Al-Zyoud \& Sengonca,
2004). On the other hand, B. tabaci eggs were more suitable for Serangium japonicum than nymphs (Jing et al., 2004). Two other species, Clitostethus arcuatus (Kirk \& Thistlewood, 1999) and Delphastus catalinae (Hoelmer et al., 1993) feed on all developmental stages of $B$. tabaci and reproduction of the latter depends on high whitefly densities (Gerling \& Stern, 1993; Heinz \& Parrella, 1994). This study is the first record that $P$. japonica larvae can complete its development when feeding exclusively on $B$. tabaci nymphs. Nymphs of $B$. tabaci were more suitable prey than the eggs.

In northern China, B. tabaci and $M$. persicae often coexist both in the field and on greenhouse grown vegetables, although their relative abundance varies over time. Since $P$. japonica is an effective predator of aphids (Zhang et al., 2004), the possibility of utilizing a single natural enemy to control mixed populations of aphids and whiteflies may reduce costs when $P$. japonica is used for whitefly control in greenhouses. In addition, because $P$. japonica preys on all whitefly stages, it can survive throughout the season in absence of aphids.

Our study did not examine the effects of prey species on the reproduction of $P$. japonica, which is another criterion for an essential prey (Hodek, 1996). Adults of $P$. japonica reared on the $M$. persicae were larger than those reared on the nymphs of B. tabaci. The influence of $B$. tabaci nymphs as prey upon the reproduction of $P$. japonica needs further investigation.

ACKNOWLEDGEMENTS. We are particularly grateful to G.L. Lövei (Department of Crop Protection, Danish Institute of Agricultural Science, Flakkebjerg Research Centre, DK-4200 Slagelse, Denmark) for his critical suggestions on a previous version of the manuscript. We also extend our thanks to the anonymous reviewers and the editor for providing numerous suggestions for the manuscript improvement. This research was supported by Chinese Ministry of Science and Technology, 973 Projects (Grant No. 2002CB111407) and Beijing science and technology program (Grant No. H012010130113).

\section{REFERENCES}

Al-Zyoud F. \& Sengonca C. 2004: Prey consumption preferences of Serangium parcesetosum Sicard (Col., Coccinellidae) for different prey stages, species and parasitized prey. J. Pest Sci. 77: 197-204.

Brown J.K., Frolich D.R. \& Rosell R.C. 1995: The sweetpotato or silverleaf whiteflies: biotypes of Bemisia tabaci or a species complex? Annu. Rev. Entomol. 40: 511-534.

Byrne D.N. \& Bellows T.S. 1991: Whitefly biology. Annu. Rev. Entomol. 36: 431-457.

Dubey A.K., MisRa V.S. \& Dixit S.A. 1981: Effect of host plant on the developmental stages of Heliothis armigera. Indian $J$. Entomol. 29: 48-57.

Gerling D. \& Stern T.U. 1993: Biology of Delphastus pusillus: the influence of density on fitness. Bull. IOBC/WPRS 16: $39-42$. 
Gerling D., Alomar O. \& Arno J. 2001: Biological control of Bemisia tabaci using predators and parasitoids. Crop Prot. 20: 779-799.

Heinz K.M. \& Parrella M.P. 1994: Poinsettia (Euphorbia pulcherrima Willd. ex Koltz.) cultivar-mediated differences in performance of five natural enemies of Bemisia argentifolii Bellows and Perring, n. sp. (Homoptera: Aleyrodidae). Biol. Control 4: 305-318.

Hilje L., Costa H.S. \& Stansly P.A. 2001: Cultural practices for managing Bemisia tabaci and associated viral diseases. Crop Prot. 20: 801-812.

Hodek I. 1996: Food relationships. In: Hodek I. \& Honěk A. (eds): Ecology of Coccinellidae. Kluwer Academic Publishers, Dordrecht, pp. 143-238.

Hoelmer K.A., Osborne L.S. \& Yokomi R.K. 1993: Reproduction and feeding behavior of Delphastus pusillus (Coleoptera: Coccinellidae) a predator of Bemisia tabaci (Homoptera: Aleyrodidae). J. Econ. Entomol. 86: 322-329.

Jiang Y.X., Lei H., Collar J.L., Martin B., Muniz M. \& Fereres A. 1999: Probing and feeding behavior of two distinct biotypes of Bemisia tabaci (Hom., Aleyrodidae) on tomato plants. J. Econ. Entomol. 92: 357-366.

Jing Y., Huang J. \& Huang L.Y. 2002: Progress on the utilization of biological control of beneficial Coccinellids. J. Shanxi Agric. Univ. 22: 299-303 [in Chinese, English abstr.].

Jing Y., Huang J., Han J.C. \& Ma R.Y. 2004: Predation of Serangium japonicum on Bemisia tabaci. Acta Phytophyl. Sin. 31: 225-229 [in Chinese, English abstr.].

Jones D.R. 2003: Plant viruses transmitted by whiteflies. Eur. J. Plant Pathol. 109: 195-219.

KIRK A.A. \& ThisTlewood H. 1999: Development of host specificity tests for predators as biological control agents: an example for Clitostethus arcuatus (Rossi) (Coleoptera: Cocci- nellidae) on Bemisia tabaci Gennadius (Homoptera: Aleyrodidae) B-biotype species complex. Bull. IOBC/WPRS 22: 33.

Legaspi J.C., Legaspi JR B.C., Meagher JR R.L. \& Ciomperlik M.A. 1996: Evaluation of Serangium parcesetosum (Coleoptera: Coccinellidae) as a biological control agent of the silverleaf whitefly (Homoptera: Aleyrodidae). Environ. Entomol. 25: 1421-1427.

OBRYCKI J.J. \& KRING T.J. 1998: Predaceous Coccinellidae in biological control. Annu. Rev. Entomol. 43: 295-321.

OMKar \& SRIVASTAVA S. 2003: Influence of six aphid prey species on development and reproduction of a ladybird beetle, Coccinella septempunctata. BioControl 48: 379-393.

Palumbo J.C., Horowitz A.R. \& Prabhaker N. 2001: Insecticidal control and resistance management for Bemisia tabaci. Crop Prot. 20: 739-765.

Ren S.X., Wang Z.Z., Qiu B.L. \& XIao Y. 2001: The pest status of Bemisia tabaci in China and non-chemical control strategies. Entomol. Sin. 8: 279-288.

Secker A.E., Bedford I.D., Markham P.G. \& de William M.C. 1998: Squash, a reliable field indicator for the presence of $B$ biotype of tobacco whitefly, Bemisia tabaci. In: Brighton Crops Protection Conf. Pests and Diseases. British Crop Protection Council, Farnham, UK, pp. 837-842.

THOMPson W.R. 1951: The specificity of host relationships in predaceous insects. Can. Entomol. 83: 262-269.

Wu X.X., Hu D.X., Li Z.X. \& SHen Z.R. 2002: Using RAPD-PCR to distinguish biotypes of Bemisia tabaci (Homoptera: Aleyrodidae) in China. Entomol. Sin. 9(3): 1-8.

Zhang S.Z., Wu J.X., Zhang Q., Jiang J.X., Xu X.L. \& Chen J.A. 2004: Research progress of biology, ecology and application on Propylea japonica (Thunberg). Agr. Res. Arid Areas 22: 206-210 [in Chinese, English abstr.].

Received June 2, 2006; revised and accepted October 3, 2006 